\title{
SISTEM INFORMASI PROFIL MAHASISWA PADA PENILAIAN PENGUJI PESSTA+ DI PERGURUAN TINGGI
}

\author{
Hani Dewi Ariessanti ${ }^{1}$, Aris Martono ${ }^{2}$, Danang Suprayogi ${ }^{3}$ \\ Dosen Sistem Komputer STMIK Raharja ${ }^{1}$, Dosen Teknik Informatika STMIK Raharja ${ }^{2}$, \\ Mahasiswa Sistem Komputer STMIK Raharja ${ }^{3}$ \\ e-mail: hani.dewi@raharja.info ${ }^{1}$, aris.martono@raharja.info ${ }^{2}$, \\ danang.suprayogi@raharja.info ${ }^{3}$
}

\begin{abstract}
ABSTRAK
Penyampaian informasi merupakan sebuah hal yang penting pada sebuah sistem. Sebuah sistem yang baik yaitu dapat berkomunikasi kepada penggunanya dengan menyampaikan informasi dengan benar dan jelas. Pada sistem penilaian penguji yang terdapat di Perguruan Tinggi Raharja sebelumnya sistem masih kurang memberikan informasi perihal profil dari mahasiswa sidang Skripsi dan Tugas Akhir. Penyampaian informasi yang kurang tersebut dirasa kurang membuat sistem yang telah berjalan sebelumnya tidak dapat berkomunikasi kepada penggunanya. Maka dari itu perlu dikembangkanlah sistem informasi profil mahasiswa supaya dapat berkomunikasi kepada penggunanya dengan jelas. Setelah sistem penilaian penguji yang sudah dikembangkan menjadi online maka sistem informasi profil mahasiswa juga dikembangkan menjadi online dengan menambahkan beberapa informasi yang dapat membuat sistem menjadi lebih berkomunikasi kepada penggunanya. Penelitian untuk mengembangkan sistem informasi profil mahasiswa pada penilaian penguji sidang menggunakan metode penelitian observasi, wawancara dan studi pustaka. Peneliti melakukan observasi dengan melihat kekurangan sistem, lalu melakukan wawancara kepada stakeholder, selanjutnya peneliti mencari penelitian serupa guna untuk memecahkan permasalahan yang telah didapat. Diharapkan setelah diterapkan pada sistem Penilaian Penguji penyampaian informasi perihal profil mahasiswa sidang Skripsi dan Tugas Akhir dapat lebih baik dan lebih jelas. Karena informasi mengenai profil mahasiswa sangatlah penting bagi penguji dalam memberikan nilai sidang kepada mahasiswa sidang Skripsi dan Tugas Akhir.
\end{abstract}

Kata Kunci-Informasi, Profil Mahasiswa, PESSTA+

\begin{abstract}
Submission of information is an important thing in a system. A good system that is able to communicate to its users by conveying information correctly and clearly. In the examiner rating system found in Raharja College before the system still did not provide information about the profile of the Thesis and Final Project students. Submitting the lack of information is felt to make the previously running system unable to communicate to its users. Therefore it is necessary to develop a student profile information system so that it can communicate to its users clearly. After the examiner assessment system that has been developed becomes online, the student profile information system is also developed online by adding some information that can make the system more communicating to its users. Research to develop a student profile information system on the assessment of trial examiners using observational research methods, interviews and literature studies. The researcher made observations by looking at the shortcomings of the system, then conducting interviews with stakeholders, then the researchers sought similar research in order to solve the problems that had been obtained. It is expected that after being applied to the Testing Assessment system, the delivery of information regarding the profile of the Thesis trial and Final Project students can be better and clearer. Because
\end{abstract}


information about student profiles is very important for examiners in providing trial scores to Thesis and Final Project students.

Keywords - Information, Student Profile, PESSTA +

\section{Pendahuluan}

Setiap sistem yang dibuat pasti terdapat sebuah sistem informasi yang menyampaikan sebuah informasi perihal objek yang diinginkan. Menurut Hengki Tamando Sihotang (2018) Sistem Informasi adalah kumpulan elemen yang saling berhubungan satu sama lain yang membentuk satu kesatuan untuk mengintegrasikan data, memproses dan menyimpan serta mendistribusikan informasi. Jadi Sistem Informasi merupakan sebuah sekumpulan elemen yang saling berkaitan untuk memproses dan menyimpan sebuah data sehingga dapat disajikan menjadi sebuah informasi yang jelas.

Penyampaian informasi merupakan hal yang sangat penting dimiliki oleh sebuah sistem. Sistem yang dibuat sangat baik akan dapat menyampaikan informasi yang baik dan jelas kepada penggunanya sehingga dapat berkomunikasi dengan baik. Penyampaian informasi yang baik merupakan informasi yang didapat dari data-data yang sudah jelas atau tidak palsu. Data yang disampaikan harus jelas karena agar informasi yang disampaikan dapat ditangkap dengan baik oleh penggunanya.

Pada penilaian penguji sidang penyampaian informasi sangatlah penting terlebih menyampaikan informasi profil mahasiswa sidang Skripsi dan Tugas Akhir. Informasi mengenai profil mahasiswa sidang sangatlah penting dikarenakan dengan adanya informasi tersebut dewan penguji dapat memberikan penilaian yang tepat untuk mahasiswa sidang skripsi dan tugas akhir.

Penilaian Penguji yang terdapat pada Perguruan Tinggi Raharja yang berjalan saat ini masih menggunakan jaringan lokal sehingga dewan penguji hanya dapat diakses di kampus. Penyampaian Informasi pada penilaian penguji yang telah berjalan dirasa kurang karena penguji hanya dapat mengakses sistem di kampus, sehingga tidak dapat dilihat dimanapun dan kapanpun. Maka dari itu sistem perlu dilakukannya pengembangan termasuk juga sistem penyampaian informasi profil mahasiswa.

Penyampaian informasi profil mahasiswa pada sistem penilaian penguji yang telah berjalan saat ini dirasa kurang dapat berkomunikasi kepada penggunanya. Hal itu dikarenakan informasi yang disajikan sangat kurang dan masih belum terintegrasi dengan sistem penilaian sidang sebelumnya. Sehingga membuat proses menyampaikan informasi dari sistem kepada penggunanya dalam hal ini yakni dewan penguji masih sangat minim atau kurang.

Pada sistem penilaian sidang terdapat 3 fitur yang saling terintegrasi yakni penilaian objektif, penilaian pembimbing, serta penilaian penguji. Dikarenakan sistem penilaian objektif dan penilaian pembimbing sudah dikembangkan menjadi online sehingga penyampaian informasi menjadi tidak informatif dan sistem tidak dapat berkomunikasi dengan baik kepada dewan penguji. Setelah sistem Penilaian Sidang sudah sepenuhnya bertransformasi menjadi online, saat ini sistem sudah saling terintegrasi dan penyampaian informasi dapat lebih komunikatif dan informatif.

Dengan sistem yang sudah saling terintegrasi membuat penulis berusaha membuat penyampaian informasi profil mahasiswa sidang skripsi dan tugas akhir harus dapat lebih 
informatif dan komunikatif. Dengan penyampaian informasi yang jelas maka dewan penguji dapat terbantu dalam memberikan penilaian kepada mahasiswa sidang skripsi dan tugas akhir.

\section{Metode Penelitian}

Dalam melakukan sebuah penelitian digunakan beberapa metode penelitian guna untuk melancarkan proses penelitian agar tujuan yang diinginkan dapat dicapai. Terdapat beberapa metode penelitian yang digunakan pada penelitian kali ini yakni observasi, wawancara dan studi pustaka.

Penulis melakukan observasi ke Perguruan Tinggi Raharja guna melihat sistem informasi profil mahasiswa pada penilaian penguji yang sedang berjalan dan melihat kekurangan pada sistem yang telah berjalan tersebut. Selanjutnya penulis melakukan wawancara kepada stakeholder guna mendapatkan beberapa data untuk kepentingan penelitian. Guna mengembangkan sistem informasi profil mahasiswa agar dapat berkomunikasi dengan baik kepada penggunanya penulis menggunakan metode studi pustaka yakni mencari beberapa penelitian serupa untuk mendukung penelitian ini. Beberapa literature review diantaranya sebagai berikut :

1. Penelitian yang dilakukan oleh Diah Aryani, Muhamad Arif Nurdin, Pandi Baskara (2017) dengan judul "SISTEM INFORMASI PENGELOLAAN ASET KENDARAAN BERMOTOR PADA STMIK RAHARJA TANGERANG”. Penelitian ini menjelaskan bahwa Pada Perguruan Tinggi Raharja proses laporan pengelolaan aset kendaraan bermotor yang dilakukan secara manual yang mengakibatkan proses pencarian data dan pelaporan data aset memerlukan waktu. Sehingga diusulkan sistem informasi manajemen aset kendaraan menggunakan php dan mysql. Yang bertujuan untuk mampu mengatasi kesulitan dalam mencari data yang diinginkan dan keterlambatan pemeliharaan aset kendaraan dan dalam pembuatan laporan.

2. Penelitian yang dilakukan pada tahun 2018 dengan judul "Pemanfaatan RinfoSheet Sebagai Media Informasi Laporan Penjualan Barang pada Raharja Internet Cafe" oleh Untung Rahardja, Eka Purnama Harahap, dan Dini Intan Pratiwi. Pada penelitian ini membahas tentang pemanfaatan RinfoSheet sebagai media informasi untuk pencatatan laporan akuntansi karena dapat dilakukan dimana saja dan kapan saja. Tidak hanya itu data laporan yang telah diinput dapat disimpan secara online.

3. Pada Tahun 2017 Untung Rahardja, Qurotul Aini dan Lily Ratna Sulastrini melakukan penelitian dengan judul "Penerapan Inbound Official Site Sistem Informasi Untuk Meningkatkan Rank Webometrics". Penelitian ini membahas inbound untuk website Sistem Informasi, karena dengan adanya banyak inbound tentunya akan membuat official site Sistem Informasi lebih dikenal lagi khususnya bagi para Pribadi Raharja jurusan Sistem Informasi sebagai wadah untuk mendapatkan informasi yang akurat.

4. Penelitian yang dilakukan oleh Untung Rahardja, Muhamad Yusup dan Ana Nurmalina pada tahun 2018 "PENERAPAN iLEARNING SURVEY (iSur) DALAM MENINGKATKAN KUALITAS SISTEM INFORMASI SELAMA PROSES PEMBELAJARAN DI PERGURUAN TINGGI RAHARJA". Penelitian ini membahas tentang Untuk menilai sejauh mana kampus ini telah berkembang dan bagaimana 
kinerja dosen dalam mengajarkan mahasiswa/i di kelas, serta iLearning Survey (isur) dapat dijadikan sebuah media informasi yang valid untuk sebuah penilaian di seluruh aktivitas perguruan tinggi Raharja.

5. Penelitian yang dilakukan pada tahun 2018 oleh Indri Handayani, Erick Febriyanto dan Kevin Rama Putra Solichin yang berjudul "Penerapan Viewboard Sebagai Media Informasi Sidang Skripsi Pada PESSTA+ di Perguruan Tinggi”. Penelitian ini membahas tentang merancang sebuah Viewboard, diharapkan dapat memberikan gambaran informasi mengenai kegiatan sidang skripsi / tugas akhir dari PESSTA +, untuk memberikan solusi, mengevaluasi proses dan memonitoring kinerja proses yang sedang berjalan.

6. Penelitian dengan judul "Prototipe Deteksi Curah Hujan Dan Sistem Informasi Berbasis Pada ESP8266 Di BMKG Klimatologi Geofisika Klas I Tangerang” dilakukan oleh Indri Handayani, Hendra Kusumah dan Nursohit pada TAhun 2018 membahas tentang mengembangkan peralatan yang murah dan untuk memberikan informasi secara langsung mengenai keadaan cuaca di daerah tertentu. Informasi keadaan cuaca apakah terjadinya hujan atau tidak, ini sangat berguna untuk masyarakat yang ingin berpergian ke suatu tempat atau wilayah tertentu.

7. Penelitian dengan judul "PEMANFAATAN AUGMENTED REALITY SEBAGAI MEDIA INFORMASI KAMPUS MENGGUNAKAN BROSUR” pada tahun 2015 dilakukan oleh Latius Hermawan dan Mochamad Hariadi. Penelitian ini membahas dengan memanfaatkan teknologi $\mathrm{AR}$, informasi pada brosur yang biasa digunakan untuk memberikan informasi kepada pembaca sebenarnya dapat ditambahkan dengan bentuk informasi 3D yang ditampilkan secara virtual, sehingga kampus dapat melengkapi informasi penting yang belum termuat pada brosur. Hasil yang didapat menunjukan bahwa pembaca dapat melihat bagian brosur AR dengan detil serta lingkungan pada brosur juga akan terasa lebih hidup dengan adanya animasi pendukung seperti gedung, pohon, dan lain sebagainya.

8. Penelitian yang dilakukan oleh M. Kirom (2014) dengan judul "SISTEM INFORMASI GEOGRAFIS PEMETAAN SUARA PEMILUKADA BERBASIS OPEN SOURCE DI KABUPATEN JOMBANG" Membahas tentang Sistem Informasi Geografis (SIG) didefinisikan sebagai alat atau media untuk memasukkan, menyimpan, mengambil, memanipulasi, menganalisa dan menampilkan data-data beratribut geografis (data spasial). SIG dapat menampilkan informasi yang beragam dalam suatu bidang gambar. Salah satu sistem informasi yang dapat dikembangkan untuk memberikan informasi hasil suara pemilihan umum kepala daerah di Kabupaten Jombang adalah dengan menggunakan Sistem Informasi Geografis (SIG) berbasis open source.

\section{HASIL DAN PEMBahasan}

\subsection{Analisa Permasalahan}

Dengan perkembangan teknologi yang semakin pesat saat ini penyampaian informasi haruslah akurat dan jelas. Tidak hanya itu tampilan yang disajikan untuk menyampaikan informasi haruslah enak dilihat agar pengguna dapat dengan mudah dipahami. Pada sistem penilaian penguji sidang pada PESSTA Lokal sistem informasi yang disajikan sangatlah minim 
hanya terdiri dari beberapa informasi, sehingga penguji dirasa kurang mendapatkan informasi tentang mahasiswa sidang skripsi dan tugas akhir.

Dari permasalahan diatas penulis ingin mengembangkan sistem informasi profil mahasiswa bersamaan dengan sistem penilaian penguji yang sudah berkembang menjadi online. Sehingga tampilan untuk sistem informasi dapat lebih enak dilihat dan lebih mudah menyampaikan informasi kepada dewan penguji sidang Skripsi dan Tugas Akhir.

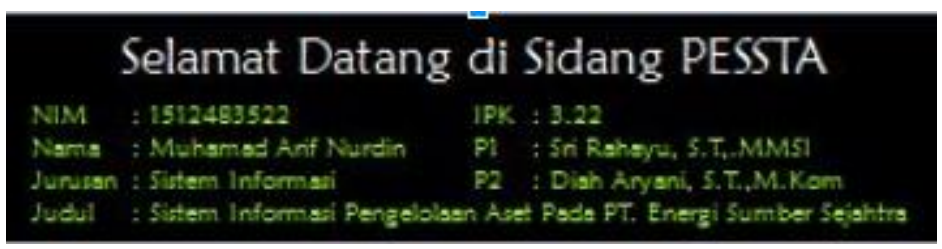

Gambar 1. Tampilan Sistem Informasi PESSTA Lokal

Gambar diatas merupakan tampilan sistem informasi yang terdapat pada PESSTA Lokal dimana informasi yang disajikan sangat minim. Terdapat beberapa informasi yang diberikan pada sistem tersebut diantaranya NIM, Nama Jurusan Judul, IPK, Pembimbing 1 dan Pembimbing 2. Dengan sedikitnya informasi tersebut membuat dewan penguji kurang memperoleh informasi yang disajikan.

\subsection{Pemecahan Masalah}

Setelah diadakannya penelitian terhadap permasalahan yang dihadapi, Sistem penilaian penguji yang sebelumnya menggunakan jaringan kini sudah dapat diakses secara online pada website PESSTA+. Pengembangan juga terjadi pada sistem informasi profil mahasiswa yang terdapat pada penilaian penguji. Sistem yang sebelumnya hanya menampilkan beberapa informasi saja kepada penggunanya. Kini sistem dapat menampilkan informasi yang lebih mudah dipahami dan lebih jelas.

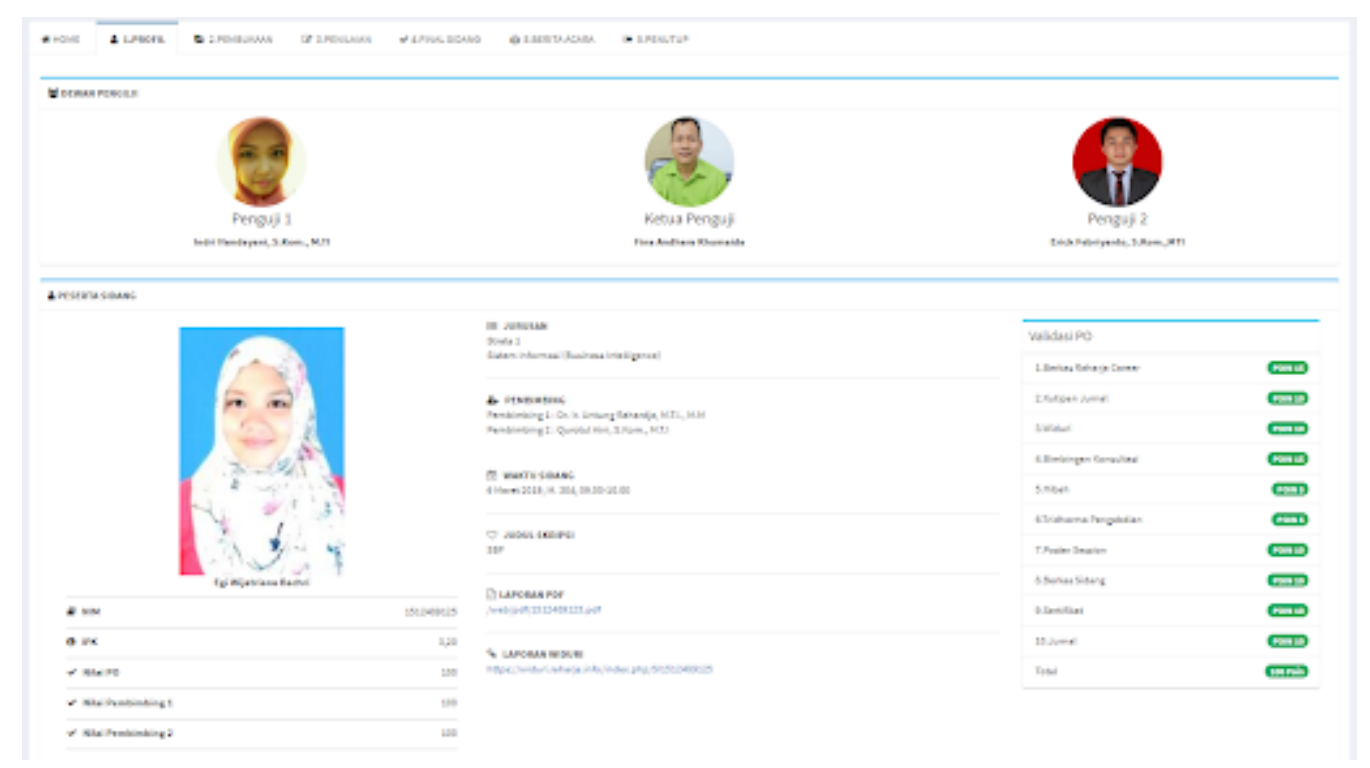

Vol 5 No 1 - Februari 2019 


\section{Gambar 2. Tampilan Informasi Profil Mahasiswa pada Penilaian Penguji PESSTA+}

Penerapan sistem informasi pada penilaian penguji PESSTA+ dapat terlihat lebih lengkap dan lebih informatif. Hal tersebut dikarenakan sistem penilaian penguji sudah terintegrasi dengan penilaian sidang lainnya pada PESSTA+, seperti penilaian objektif dan penilaian pembimbing. Informasi yang disajikan juga dapat berkomunikasi dengan dewan penguji sidang. Seperti dewan penguji yang menguji mahasiswa sidang.

to ncwaw pencual

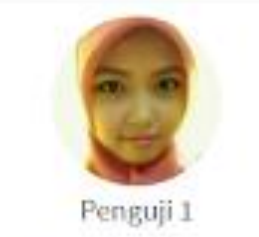

Indri Handayani, SKom., M.TI

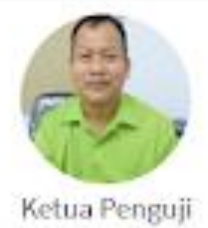

Dr. in. Sudaryono, Nend

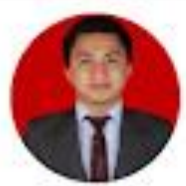

Penguii 2

rrick Febryanto, S.Kom1, NTI

Gambar 3. Tampilan Informasi Dewan Penguji Sidang

Gambar diatas merupakan tampilan daftar dewan penguji yang akan menguji mahasiswa Sidang Skripsi atau Tugas Akhir. Tampilan tersebut dapat memberitahu bahwa dewan penguji yang akan bersama mereka saat sidang. Tidak hanya itu sistem dapat menyampaikan informasi tentang profil singkat mahasiswa dari nama hingga laporan yang ia kerjakan. 


\section{PESERTA SIDANG}

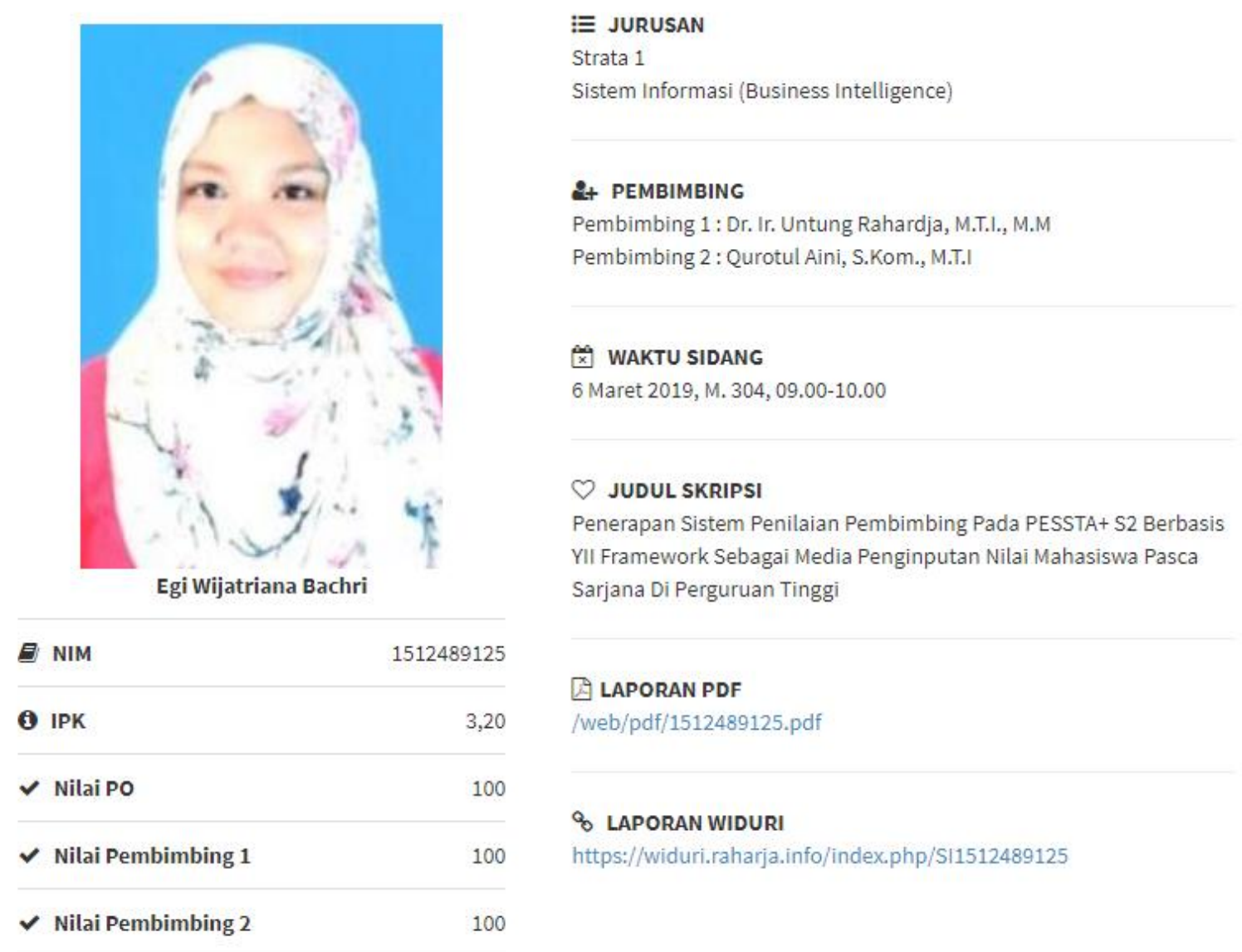

\section{Gambar 4. Tampilan Profil Mahasiswa}

Selain tampilan informasi mengenai dewan penguji, terdapat juga informasi perihal profil mahasiswa sidang Skripsi atau Tugas Akhir. Pada informasi yang disajikan terdapat beberapa point yang membuat penguji bertanya-tanya menjadi paham setelah disampaikan informasi tersebut. Informasi yang disajikan antara lain :

1. Photo profil mahasiswa yang sudah terkoneksi dengan sisplus sehingga mahasiswa dapat mengupdate profil mereka melalui sisplus ketika ingin sidang.

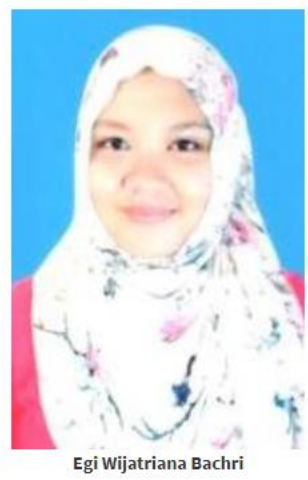

2. Nim mahasiswa yang akan sidang Skripsi dan Tugas Akhir. 
3. IPK terakhir yang diraih mahasiswa ketika mengambil Skripsi atau Tugas Akhir juga dapat dilihat oleh dewan penguji.

(i) IPK

4. Point penilaian sidang lainnya seperti point penilaian objektif dan juga penilaian pembimbing yang sudah terintegrasi dengan PESSTA+. Dimana sistem penilaian objektif dan pembimbing sudah lebih dahulu terdapat pada PESSTA+.

$\begin{array}{ll}\text { Nilai Po } & 100\end{array}$

Nilai Pembimbing $1 \quad 100$

Nilai Pembimbing $2 \quad 100$

5. Terdapat informasi jenjang perkuliahan yang mahasiswa tersebut ambil serta jurusan dan konsentrasi yang ia pilih.

\section{:三 JURUSAN}

Strata 1

Sistem Informasi (Business Intelligence)

6. Nama pembimbing 1 dan 2 dari mahasiswa tersebut, sehingga dewan penguji dapat mengetahui siapa pembimbing mahasiswa tersebut yang memberikan nilai penilaian pembimbing.

+ PEMBIMBING

Pembimbing 1 : Dr. Ir. Untung Rahardja, M.T.I., M.M

Pembimbing 2 : Qurotul Aini, S.Kom., M.T.I

7. Waktu sidang komprehensif dari mahasiswa tersebut juga terdapat pada sistem informasi tersebut

WAKTU SIDANG

6 Maret 2019, M. 304, 09.00-10.00 
8. Judul skripsi dari mahasiswa sidang skripsi atau tugas akhir pun dapat dilihat oleh dewan penguji.

\section{JUDUL SKRIPSI}

Penerapan Sistem Penilaian Pembimbing Pada PESSTA+ S2 Berbasis

YII Framework Sebagai Media Penginputan Nilai Mahasiswa Pasca

Sarjana Di Perguruan Tinggi

9. Laporan mahasiswa yang sudah dikumpulkan di RPU dan juga laporan yang sudah di upload di Widuri juga dapat dilihat oleh dewan penguji.

\section{LAPORAN PDF}

/web/pdf/1512489125.pdf

\section{\& LAPORAN WIDURI}

https://widuri.raharja.info/index.php/SI1512489125

Tidak hanya itu selain beberapa informasi diatas dewan penguji juga dapat melihat validasi penilaian objektif mahasiswa sidang skripsi dan tugas akhir.

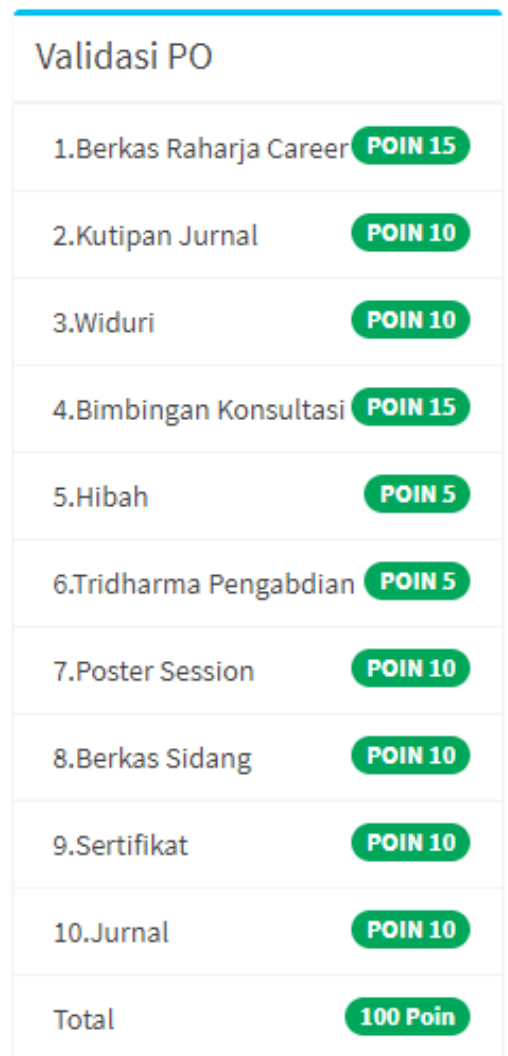

Gambar 5. Validasi PO Mahasiswa 
Gambar diatas merupakan informasi mengenai penilaian objektif berkas sidang yang mahasiswa sudah upload sebelum sidang pada PESSTA+. Jika pada sistem sebelumnya dewan penguji melakukan cek berkas sidang, saat ini dewan penguji tidak perlu melakukan itu karena PESSTA+ sudah menyediakannya, sehingga dewan penguji hanya perlu melihat berapa poin yang didapat oleh mahasiswa sidang skripsi dan tugas akhir.

Untuk membuat tampilan sistem informasi diatas memang sangatlah tidak mudah, penulis harus berusaha agar sistem dapat berkomunikasi dengan dewan penguji ketika sidang komprehensif berlangsung. Script untuk membuat sistem tersebut dapat dilihat dibawah ini.

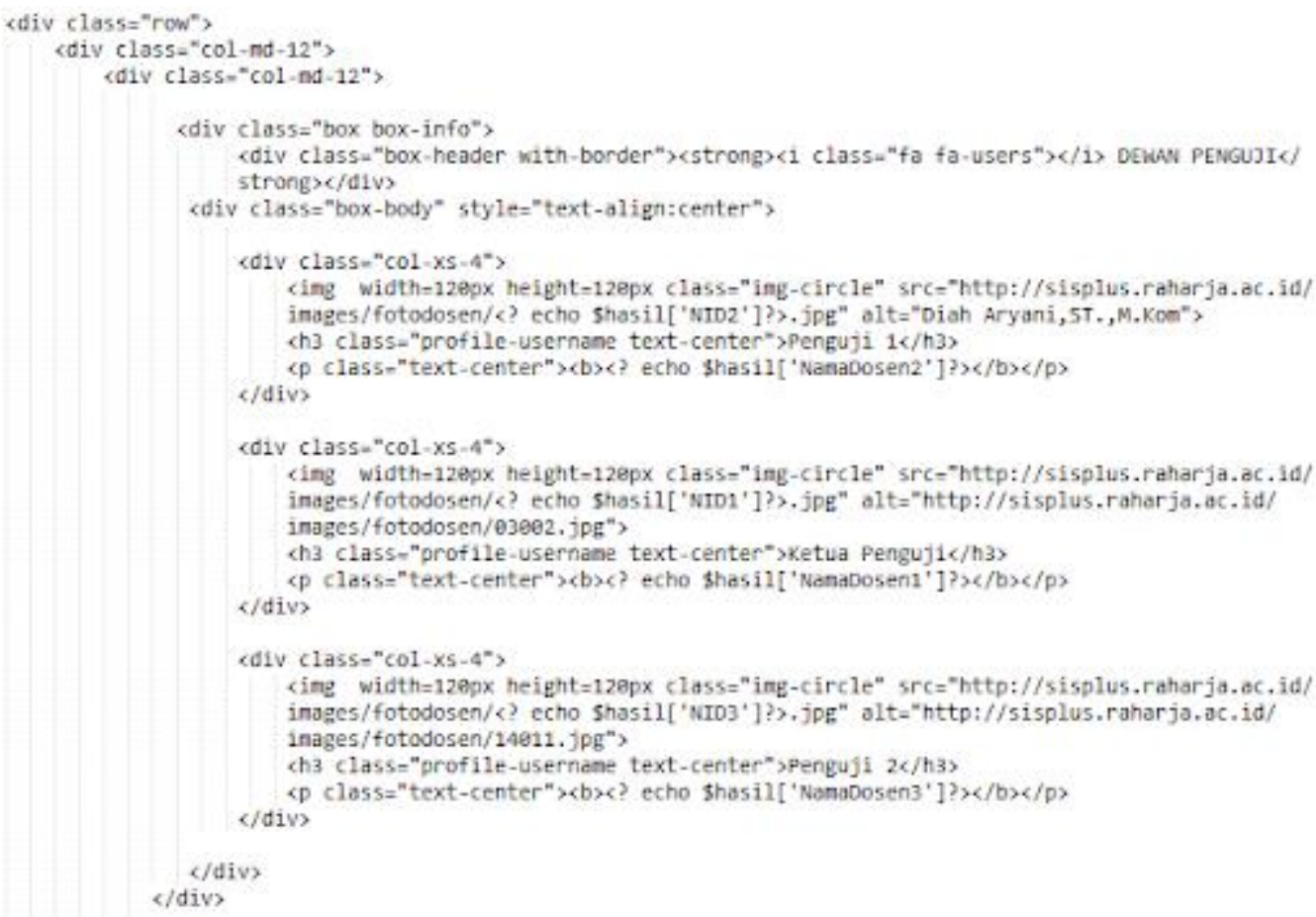


¿div class="box box-info">

〈div class-"box-header with-border" $>$ (strong $\rangle<1$ class-"fa fa-user" $></ 1\rangle$ PESERTA SIDANG $/$ strong $\rangle</$ div>

〈div class="box-body" >

<div class-"col-xs $4^{*}$ style-" ,

udiv class="box-body box-profile"

ecenter:

<ing width-22epx height-220px class"" ing responsive " srce"http://sisplus.

raharja.ac.id/images/fotomh/<? eeho sf?>.jpg" alt="User profile picture"s \&/centery

$\langle Q$ class-"text-center" $>\langle b\rangle\langle$ ? echo Shasi1['Nana"] $></ b></ 0\rangle$

u1 class="1ist-group 1 ist-group-unbordered",

<li class="list-group-item">

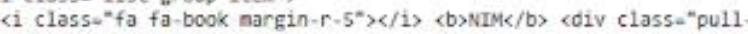

right" $>$ ? echo $3 f ?></$ diviv

$</ 1 i$

(11 c1ass="1ist-group-iten"

(i) class="fa fa-info-circle margin-r-5" $>$ c/is cbsTPK </b c div class="pu11right" $><$ ? echo shasil[ [IPK']? $></$ div $>$

$\langle/ 11\rangle$

(1i c1ass="1ist-group-iten"

ci class="fa fa-check marein-r-5" $\times c /$ i $\rangle\langle b \times$ Nilai po</b $\rangle$ <div class="pull-

right" $><$ ? echo sej['po']? $>\langle/ d i v\rangle$

$</ 11\rangle$

(1i c1ass="1ist-group-iten"s

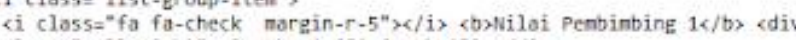

class-"pull-right" $><$ ? echo \$ej[ 'ejpenb1']? $></$ div

$</ 11\rangle$

C1i class="1ist-eroup-iten"

$\left\langle i\right.$ class="fa fa-check marein- $\left.r-5^{n}\right\rangle\langle/ 1\rangle\langle b\rangle$ Niloi Penbinbing $\left.2</ b\right\rangle\langle$ div cis

$</$ div $\rangle$ (1)

$</ d i v>$

div class="col-xs-5" style="text-align: 1eft"

(strong) $<1$ class="fa fa-1ist-uI nargin-r-5" $></ 1$ ) JuRusank/strong;

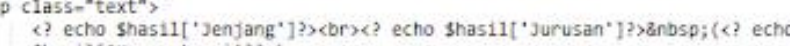
$\langle/ p\rangle$ shasil[ "Konsentrasi']??]

<strongeci class="fa fa-user-plus margin-r-5*sc/is PENBIMBTaG</strong:

<p c1ass="text"

Fenbimbing 1: <? echo shasil["pentimbing1']?>

Pentimbing 2 : $c$ ? echo shasil ['Penbimbingz']$$
\text { shr }
$$

〈strong>ci class=" $\mathrm{fa}$ fa-calendar-tines-o margin- $r-5^{*}></$ i $>$ MAKT STDAwG</strong>

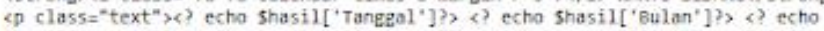
shasil[' 'Tahun']'?, \&? echo shasil['Ruang'] ?s, \&? echo shasil['waktu_nulai']? ?-<? echo Shasil[ ['waktu_selesai'] $3></ p>$

estrong $>1$ class-" fa fa-heart-0 nargin-r-5" $></ 1>$ Jubul skrIPSI</strong (p class="text" $><$ ? echo shasi1 ['Judui']? $>\langle/ p\rangle$

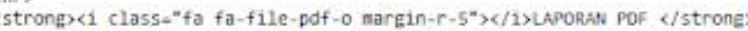

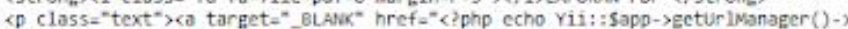

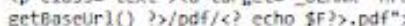

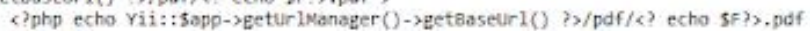
$c / a x c / p s$

cl-.

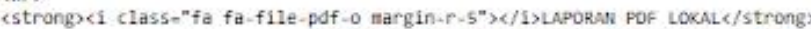

<p Class-"text"><a target =" BLAok" href-"http://172.16.

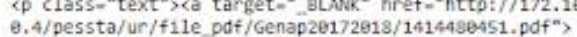

nttp://172,16,0,4/pessta/ur/file_pdf/

$\rightarrow$ Genop $20172018 / 1414450451$, pof $\langle/ 0\rangle</ 0\rangle$

hir

if (shasil[']enjang'] - 'strata I') (

sjenjang - "si";

\} eise

\}

3jenjang - "TA"

?>

<strong><i class=" fo fa-link narein- $r-5^{n}></$ i> LAPORAN wTOURI</strong>

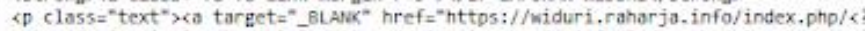

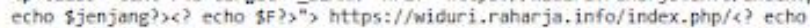
jenjang $><?$ echo $3 F\rangle>\langle/ a \times</ p>$

Gambar 6. Script Tampilan Profil Mahasiswa 


\section{KESIMPULAN}

Berdasarkan penelitian yang telah dilakukan terdapat beberapa point-point kesimpulan yang dapat penulis ambil. Berikut ini adalah beberapa kesimpulan dari pengembangan sistem informasi profil mahasiswa pada penilaian penguji pessta+ :

1. Ketika Perguruan Tinggi Raharja mengadakan Sidang Komprehensif Skripsi dan Tugas Akhir, sistem yang digunakan dan sangat penting ialah penilaian penguji. karena sistem tersebut yang digunakan oleh dewan penguji untuk menginput nilai mahasiswa sidang. Ketika menginput nilai profil mahasiswa sidang haruslah informatif karena dapat menentukan nilai mahasiswa sidang juga nantinya.

2. Setelah sistem Penilaian Penguji berkembang menjadi online dan sudah terintegrasi dengan sistem validasi sidang lainnya, penyampaian informasi profil mahasiswa menjadi sangatlah mudah karena data yang didapatkan tidaklah sulit. Tidak seperti sistem penilaian penguji sebelumnya yang masih menggunakan jaringan lokal dan sistem validasi lainnya sudah berkembang online sehingga sistem tidak saling terintegrasi.

3. Penyampaian informasi pada penilaian penguji PESSTA+ sudah lebih baik dibandingkan sistem sebelumnya. Dimana terdapat beberapa informasi tambahan yang tidak ada pada sistem sebelumnya. Tidak hanya itu sistem dapat lebih komunikatif dalam menyampaikan informasi profil mahasiswa kepada penggunanya yakni Dewan Penguji.

\section{SARAN}

Dalam penelitian alangkah baiknya terdapat saran yang diberikan oleh penulis guna dapat mengembangkan hasil penelitiannya di masa yang akan datang baik oleh penulis itu sendiri maupun penulis lainnya. Berikut merupakan beberapa saran yang dapat penulis sampaikan untuk mengembangkan penelitian ini :

1. Penyampaian profil mahasiswa yang saat ini sudah diterapkan pada penilaian penguji PESSTA+ sudah sangat baik namun perlu dikembangkan lagi agar dapat lebih komunikatif kepada penggunanya.

2. Sistem informasi yang disajikan dapat diperbanyak lagi agar dapat lebih informatif. Karena sistem yang saat ini hanya menampilkan informasi penting untuk keperluan sidang saja.

3. Penambahan informasi profil seperti nilai tertinggi dia selama kuliah boleh ditambahkan untuk pengembangan selanjutnya guna membantu penguji melihat mahasiswa tersebut unggul dalam mata kuliah apa.

\section{DAFTAR Pustaka}

[1]. Aryani, D., Setiadi, A., Adnandi, M. A., Nurjaman, I., \& Widiarso, R. T. (2014). Perancangan Sistem Informasi Pelayanan Klinik Menggunakan Model Antrian First In First Out. In Seminar Nasional Informatika Medis (SNIMed) (No. 5, pp. 19-27). 
[2]. Aryani, D., Nurdin, M. A., \& Baskara, P. (2017). SISTEM INFORMASI PENGELOLAAN ASET KENDARAAN BERMOTOR PADA STMIK RAHARJA TANGERANG. CERITA Journal, 3(1), 75-84.

[3]. Febriyanto, E., Handayani, I., \& Suprayogi, D. (2019). Aplikasi Sistem Penilaian Penguji Berbasis YII Framework Sebagai Media Input Nilai Mahasiswa Sidang Tugas Akhir Dan Skripsi Pada Perguruan Tinggi. CSRID (Computer Science Research and Its Development Journal), 10(2), 111-123.

[4]. Handayani, I., Febriyanto, E., \& Solichin, K. R. P. (2018). Penerapan Viewboard Sebagai Media Informasi Sidang Skripsi Pada PESSTA+ di Perguruan Tinggi. Technomedia Journal, 2(2), 52-62.

[5]. Handayani, I., \& Kusumah, H. (2018). Prototipe Deteksi Curah Hujan Dan Sistem Informasi Berbasis Pada ESP8266 Di BMKG Klimatologi Geofisika Klas I Tangerang. Voice Of Informatics, 7(2).

[6]. Hermawan, L., \& Hariadi, M. (2015). Pemanfaatan Augmented Reality Sebagai Media Informasi Kampus Menggunakan Brosur. In Seminar Nasional Teknologi Informasi dan Komunikasi (SENTIKA) Yogyakarta (Vol. 28).

[7]. Kharistiani, E., \& Aribowo, E. (2014). Sistem Informasi Geografis Pemetaan Potensi SMA/SMK Berbasis Web (Studi Kasus: Kabupaten Kebumen). JSTIE (Jurnal Sarjana Teknik Informatika)(E-Journal), 2(1), 41-49.

[8].Kirom, M. (2014). Sistem informasi geografis Pemetaan suara pemilukada berbasis open source di kabupaten jombang. Edutic-Scientific Journal of Informatics Education, 1(1).

[9].Rahardja, U., Aini, Q., Ariessanti, H. D., \& Khoirunisa, A. (2018). Pengaruh Gamifikasi pada iDu (iLearning Education) dalam Meningkatkan Motivasi Belajar Mahasiswa. Nusantara Journal of Computers and its Applications, 3(2).

[10]. Rahardja, U., Aini, Q., \& Khoirunisa, A. (2017). Implementasi Business Intelligence Menggunakan Highchart pada Sistem Penilaian Absensi berbasis YII Framework. CSRID (Computer Science Research and Its Development Journal), 9(2), 115-124.

[11]. Rahardja, U., Aini, Q., \& Khoirunisa, A. (2018). Monitoring Kinerja User Akuntan Menggunakan Dashboard Pada Web Based Accounting Online di Perguruan Tinggi. SATIN-Sains dan Teknologi Informasi, 4(2), 58-62.

[12]. Rahardja, U., Aini, Q., \& Sulastrini, L. R. (2017). Penerapan Inbound Official Site Sistem Informasi Untuk Meningkatkan Rank Webometrics. Technomedia Journal, 1(2), 105115.

[13]. Rahardja, U., Harahap, E. P., \& Pratiwi, D. I. (2018). Pemanfaatan RinfoSheet Sebagai Media Informasi Laporan Penjualan Barang pada Raharja Internet Cafe. Jurnal Ilmiah Teknologi Informasi Asia, 12(1), 65-74.

[14]. Rahardja, U., Yusup, M., \& Nurmaliana, A. (2014). Penerapan iLEARNING SURVEY (iSur) dalam Meningkatkan Kualitas Sistem Informasi Selama Proses Pembelajaran Di Perguruan Tinggi raharja. CCIT Journal, 7(3), 335-354.

[15]. Sihotang, H. T. (2018). Sistem Informasi Pengagendaan Surat Berbasis Web Pada Pengadilan Tinggi Medan. Journal Of Informatic Pelita Nusantara, 3(1). 